\title{
NTRK1 rearrangement in colorectal cancer patients: evidence for actionable target using patient-derived tumor cell line
}

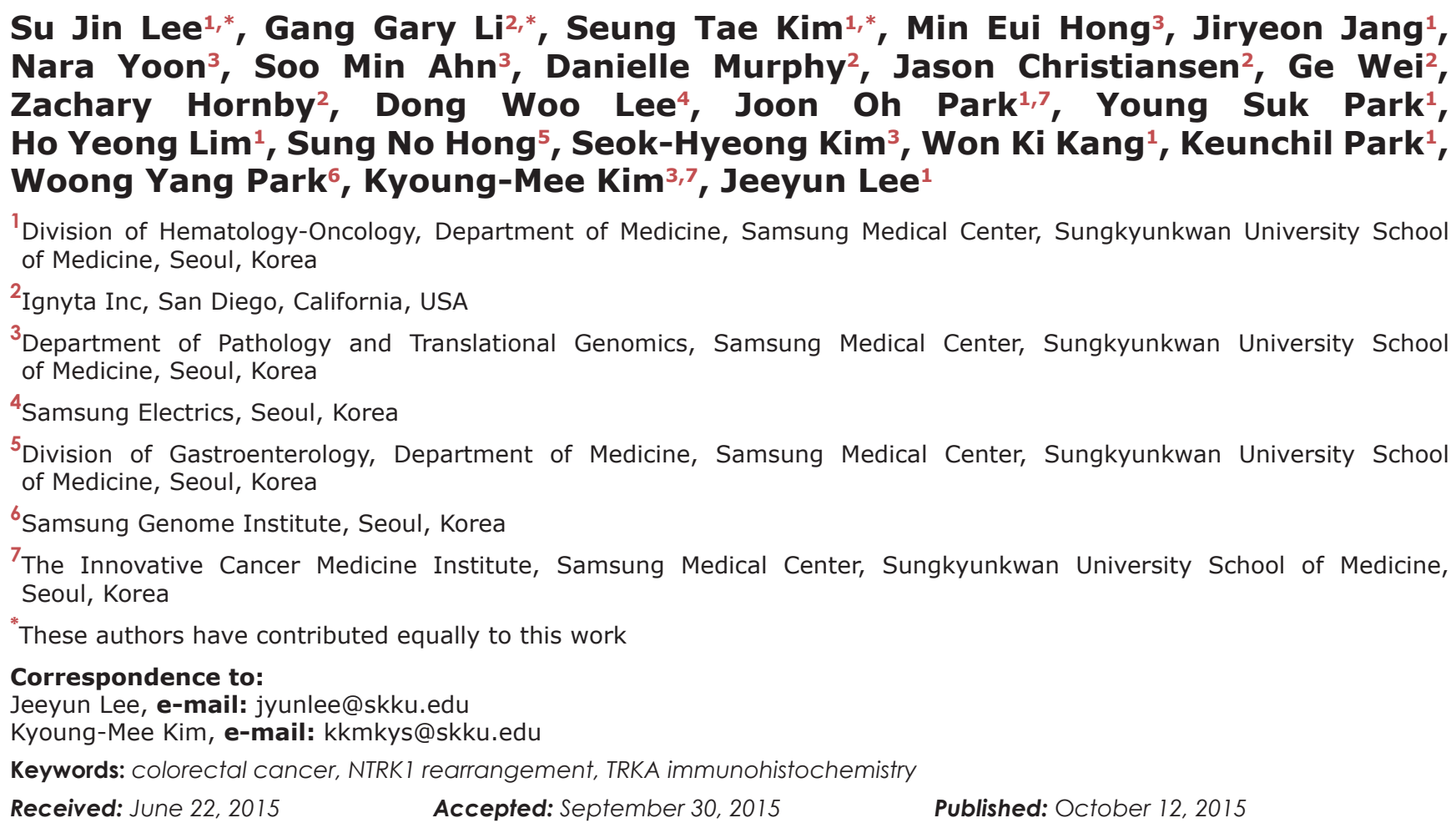

\section{ABSTRACT}

Background: We have investigated the incidence of NTRK1 rearrangements in metastatic gastrointestinal cancer patients and demonstrated the potential for clinical response of these patients to targeted therapy.

Methods: We prospectively collected tumor tissue specimens for one year and simultaneously generated patient-derived tumor cells (PDCs). Specimens were initially screened for TrkA protein expression using TrkA immunohistochemistry (IHC). In the case of TrkA IHC positive results, samples were further examined by fluorescence in situ hybridization (FISH) and next generation sequencing (NGS) to confirm the presence of NTRK1 rearrangements.

Results: From January 2014 to December 2014, a total of 74 metastatic colorectal cancer (CRC) patients and $\mathbf{6 6}$ gastric cancer (GC) patients were initially screened by TrkA IHC. Two of the 74 CRC patients (2.7\%) and one of the $66 \mathrm{GC}$ patients $(1.5 \%)$ were positive for TrkA expression by IHC. All three IHC positive cases had evidence of NTRK1 rearrangements by FISH. NGS was performed on the 3 IHC positive cases and confirmed TPM3-NTRK1 rearrangements in the two CRC cases. One GC patient with TrkA expression by IHC did not harbor an NTRK1 rearrangement. PDCs established from the NTRK1 positive CRC patients were positive for the NTRK1 rearrangement. Entrectinib, a pan-TRK inhibitor, profoundly inhibited cell proliferation of NTRK1rearranged PDCs with such inhibition associated with inactivation of TrkA, and downregulation of downstream signaling pathways. 


\section{Conclusion: TrkA IHC is an effective, initial screening method for NTRK1 rearrangement detection in the clinic. Inhibition of the TrkA kinase is a promising targeted therapy for cancer patients whose tumors harbor a NTRK1 rearrangement.}

\section{INTRODUCTION}

The Neurotrophic Tyrosine Kinase Receptor 1 gene (NTRK1) encodes the TrkA receptor, which is a member of the TRK (tropomyosin-receptor kinase) family of receptor tyrosine kinases (RTKs) that also includes TrkB (encoded by NTRK2) and TrkC (encoded by NTRK3) [1]. In normal physiological conditions, TrkA is activated through NGF-mediated dimerization, which induces autophosphorylation of specific tyrosine residues and transphosphorylation of a series of substrates, leading to activation of PI3K/ AKT, Ras/MAPK and PLC- $\gamma$ pathways [2]. The first NTRK1 gene fusion was identified in a colon cancer specimen, which had sequences from the TPM3 (non-muscle tropomyosin) gene $[3,4]$. Subsequently, NTRK1 fusions have been detected at a frequency of $12 \%$ in papillary thyroid cancer with TPM3-NTRK1 being the most common gene rearrangement [5-7]. More recently, NTRK1 rearrangements have been further identified in other tumor types, including Spitzoid melanoma (16.4\%, 23/140) [8], intrahepatic cholangiocarcinoma $(3.6 \%$, $1 / 28)$ [9], glioblastoma $(1.1 \%, 2 / 185)$ [10], pediatric high grade glioma $(7.1 \%, 8 / 112)[11]$ and sarcoma $(1 \%$, $1 / 103)$ [12]. This established evidence in various cancer types suggests that oncogenic rearrangement of NTRK1 might occur at low frequency across many other cancer types [13].

We previously reported the presence of a very rare ROS1 rearrangement in gastric cancer (GC) with an incidence of $0.8 \%$ using immunohistochemistry (IHC) screening [14]. Since then, we have incorporated IHC to identify very rare rearrangements in various tumor types. Given the rapidity, broad applicability and low costs of IHC in clinical diagnostic labs, we investigated the prevalence of NTRK1 rearrangements in gastrointestinal and colorectal cancers with TrkA IHC. Break-apart fluorescence in situ hybridization (FISH) was performed to confirm NTRK1 rearrangement in the IHC-positive cases. Additionally, NTRK1 rearrangements were further analyzed with NGS to identify the specific fusion partner.

We identified 2 CRC patients that have TPM3-NTRK1 gene rearrangements out of 74 CRC patients in this study (2.7\% prevalence). Patient derived cells (PDC) from one of these patients demonstrate a targeted tumor cell response, in both 2-D and 3-D experiments, to the TrkA inhibitor, entrectinib. These data demonstrate that NTRK1 gene rearrangements in CRC patients are sensitive to treatment with entrectinib.
RESULTS

\section{Patients' characteristics}

A total of 66 patients with $\mathrm{GC}$ and 74 patients with colorectal cancer (CRC) were included in this study. Of 66 patients with GC, 45 patients $(68.2 \%)$ were male with median age of 56 years (range, $30-80$ years). Most of the patients were stage III/IV (93.8\%) and poorly differentiated $(80.3 \%)$. Most common metastatic sites were as follows in the order of frequency: peritoneal seeding $(47.0 \%)$, liver $(27.3 \%)$, lymph node $(22.7 \%)$, ovary $(9.1 \%)$, lung $(4.5 \%)$ and bone $(4.5 \%)$. Detailed characteristics of patients are shown in Table 1. In the CRC group, median age was 60 years (range, $19-82$ years) and the male-to-female ratio was 0.85 . Primary site of disease is colon in 47 patients $(63.5 \%)$ and rectum in 25 patients $(33.8 \%)$. Initial stage was mostly stage III $(33.8 \%)$ or IV $(60.8 \%)$, and primary resection was performed in 59 patients (79.7\%). Most patients showed good to moderate differentiation $(83.8 \%)$. KRAS mutation was detected in $36.6 \%$, and $B R A F$ mutation was detected in $1.7 \%$. Most common metastatic sites were as follows: liver (47.3\%), lung (37.8\%), lymph node (29.7\%), peritoneal seeding $(20.3 \%)$, ovary $(12.2 \%)$ and bone $(5.4 \%)$.

\section{Identification of TrkA-positive cases}

With five primary antibodies, we set up IHC with different conditions and found panTRK (C17F1) from Cell signaling as one of the most sensitive and specific primary antibody and adopted this for screening. We found two out of 74 CRCs $(2.7 \%)$ and one out of 66 GCs (1.5\%) positive for Trk IHC. Representative photograph of Trk protein expression by IHC is shown in Figure 1. In these Trk $(+)$ cases, FISH analysis showed break-apart of NTRK1 gene in three out of four examined cases; $68 \%$ (Patient \#1, Figure 2), 20\% (Patient \#2), and 20\% (Patient \#3) of examined tumor cells.

\section{Characteristics of NTRK1-rearranged cancer patients}

Patient \#1. The first case is a 72-year-old male patient who presented initially with stage III KRAS wild-type, $B R A F$ wild-type ascending colon cancer in year 2013. He underwent right hemicolectomy, and the pathology revealed AJCC stage IIIB. He recurred with multiple cervical, left supraclavicular, retroperitoneal, intra-abdominal lymph node metastases after 5 cycles of adjuvant XELOX (capecitabine and oxaliplatin) chemotherapy. The chemotherapy regimen 
Table 1: Characteristics of GI cancer patients $(N=140)$

\begin{tabular}{|c|c|c|c|}
\hline \multicolumn{3}{|c|}{ Gastric cancer $(N=66)$} & \multirow{2}{*}{$\frac{\text { Colon Cancer }(N=74)}{\text { Number }(\%)}$} \\
\hline Characteristic & Number (\%) & Characteristic & \\
\hline $\begin{array}{l}\text { Age (years) } \\
\text { Median, (range) }\end{array}$ & $56(30-80)$ & $\begin{array}{l}\text { Age (years) } \\
\text { Median, (range) }\end{array}$ & $60(19-82)$ \\
\hline $\begin{array}{l}\text { Sex } \\
\quad \text { Male } \\
\text { Female }\end{array}$ & $\begin{array}{l}45(68.2) \\
21(31.8)\end{array}$ & $\begin{array}{l}\text { Sex } \\
\quad \text { Male } \\
\text { Female }\end{array}$ & $\begin{array}{l}34(45.9) \\
40(54.1)\end{array}$ \\
\hline $\begin{array}{l}\text { Primary site } \\
\text { Upper } 1 / 3 \\
\text { Middle } 1 / 3 \\
\text { Lower } 1 / 3 \\
\text { Whole } \\
\text { Primary resection } \\
\text { Yes } \\
\text { No }\end{array}$ & $\begin{array}{l}15(23.8) \\
17(27.0) \\
29(46.0) \\
2(3.2) \\
\\
23(34.8) \\
43(65.2)\end{array}$ & $\begin{array}{l}\text { Primary site } \\
\text { Appendix } \\
\text { A-Colon } \\
\text { T-Colon } \\
\text { D-Colon } \\
\text { S-Colon } \\
\text { Rectum } \\
\text { Primary resection } \\
\text { Yes } \\
\text { No }\end{array}$ & $\begin{aligned} 2 & (2.7) \\
14 & (18.9) \\
6 & (8.1) \\
5 & (6.8) \\
22 & (29.7) \\
25 & (33.8) \\
59 & (79.7) \\
15 & (20.3)\end{aligned}$ \\
\hline $\begin{array}{l}\text { Initial stage } \\
\text { III } \\
\text { IV } \\
\text { Unknown }\end{array}$ & $\begin{array}{c}13(20.0) \\
48(73.8) \\
4(6.1)\end{array}$ & $\begin{array}{l}\text { Initial stage } \\
\text { III } \\
\text { IV } \\
\text { Unknown }\end{array}$ & $\begin{array}{c}25(33.8) \\
45(60.8) \\
4(5.6)\end{array}$ \\
\hline $\begin{array}{l}\text { Differentiation } \\
\text { Well to moderately } \\
\text { differentiated } \\
\text { Poorly differentiated }\end{array}$ & $\begin{array}{l}13(19.7) \\
53(80.3)\end{array}$ & $\begin{array}{l}\text { Differentiation } \\
\text { Well to moderately } \\
\text { differentiated } \\
\text { Poorly differentiated } \\
\text { Mucinous }\end{array}$ & $\begin{array}{c}62(83.8) \\
5(6.8) \\
4((4.1)\end{array}$ \\
\hline & & KRAS mutation $(N=71)$ & $26(36.6)$ \\
\hline & & BRAF mutation $(N=58)$ & $1(1.7)$ \\
\hline $\begin{array}{l}\text { Immunohistochemistry } \\
\text { Trk }(N=66) \\
\text { HER2 }(N=64) \\
\text { cMET }(N=62)\end{array}$ & $\begin{array}{l}2(3.0) \\
6(9.4) \\
8(12.9)\end{array}$ & $\begin{array}{l}\text { Immunohistochemistry } \\
\text { Trk }(N=74) \\
\text { HER2 }(N=70) \\
\text { cMET }(N=68)\end{array}$ & $\begin{aligned} 1 & (1.7) \\
3 & (4.1) \\
027 & (39.7)\end{aligned}$ \\
\hline $\begin{array}{l}\text { Site of metastasis } \\
\text { Peritoneal seeding } \\
\text { Lymph node } \\
\text { Liver } \\
\text { Ovary } \\
\text { Lung } \\
\text { Bone }\end{array}$ & $\begin{array}{c}31(47.0) \\
15(22.7) \\
18(27.3) \\
6(9.1) \\
3(4.5) \\
3(4.5)\end{array}$ & $\begin{array}{l}\text { Site of metastasis } \\
\text { Liver } \\
\text { Lung } \\
\text { Lymph node } \\
\text { Peritoneal seeding } \\
\text { Ovary } \\
\text { Bone }\end{array}$ & $\begin{array}{c}35(47.3) \\
28(37.8) \\
22(29.7) \\
15(20.3) \\
9(12.2) \\
4(5.4)\end{array}$ \\
\hline
\end{tabular}

has been switched to irinotecan/capecitabine chemotherapy, which stabilized the disease for 4 months, but then the disease progressed to the lymph nodes. At this time, core biopsy from a supraclavicular lymph node was performed and, after tumor confirmation, we generated PDCs from the patient. The patient has progressed to cetuximab/irinotecan chemotherapy and is now deceased. The tumor has been confirmed by NGS to harbor the previously observed TPM3NTRK1. fusion with the $5^{\prime}$ end of NTRK1, including the kinase domain, starting at exon 10 fused to exon 7 of TPM3 (see Figure 2).
Patient \#2. The second patient is a 71-year-old female who was diagnosed in 2014 with multiple axillary lymph nodes and multiple liver metastases from rectal cancer. The tumor was KRAS and BRAF wild-type. After six cycles of first-line Avastin/FOLFIRI chemotherapy (fluorouracil/ irinotecan/bevacizumab), tumor progressed to multiple lower abdominal lymphadenopathies. The patient has completed 12 cycles of second-line FOLFOX (oxaliplatin, 5-FU, leucovorin) chemotherapy with stable disease. This patient was confirmed to have TPM3-NTRK1. fusion by NGS (identical to patient \#1, see Figure 2). 

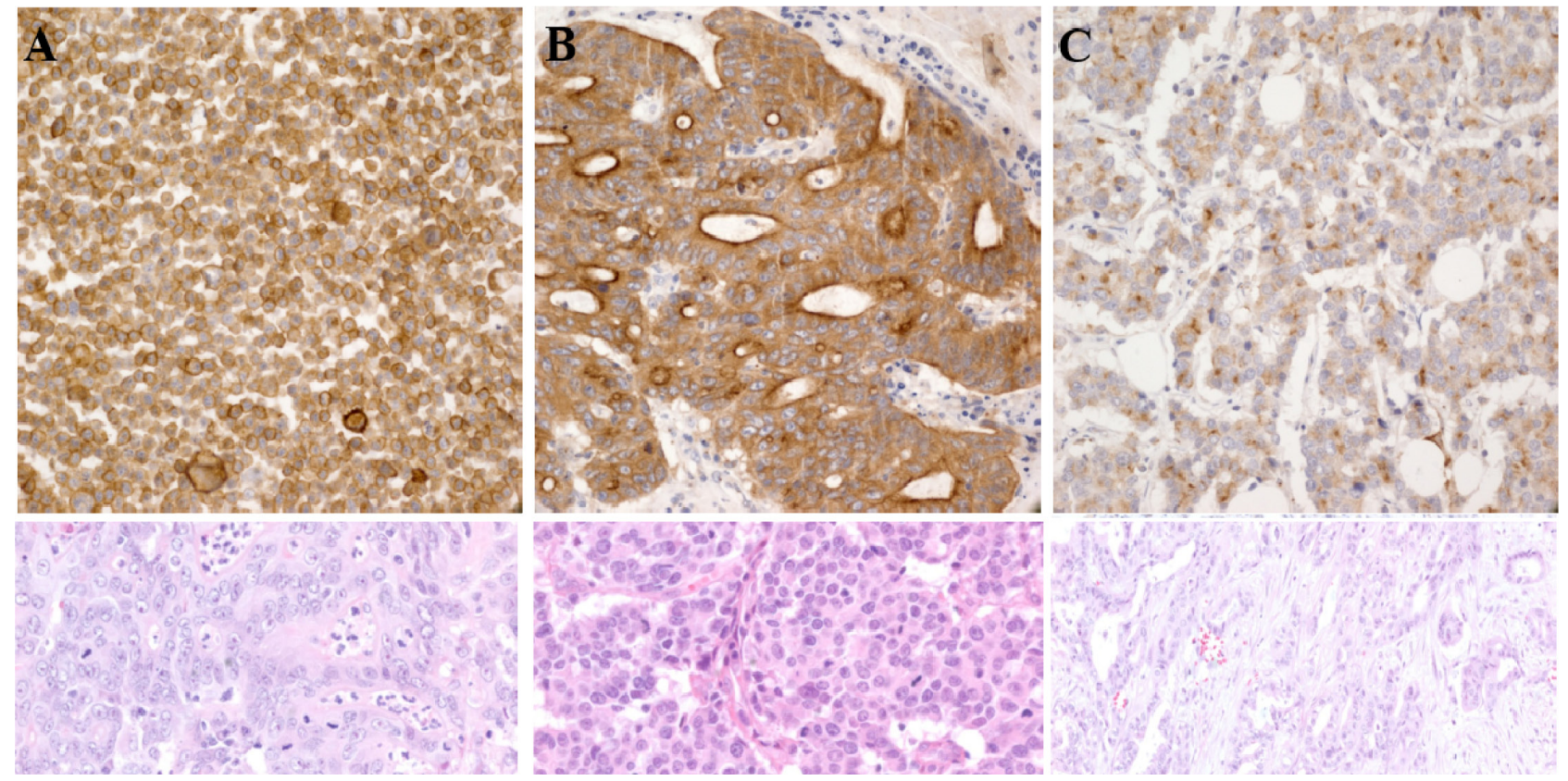

Figure 1: Trk protein expression by IHC in A. patient \#1 B. patient \#2 and C. patient \#3.

A.
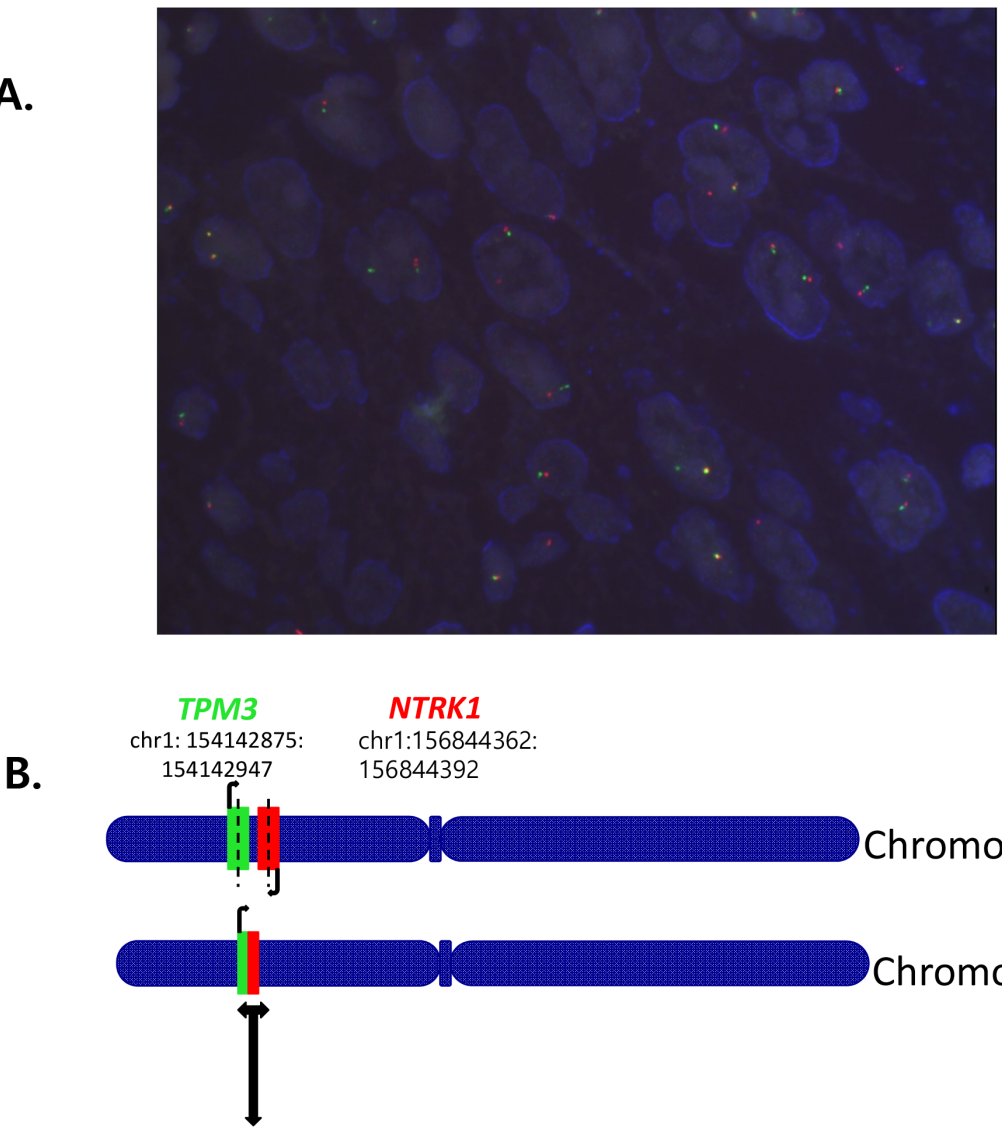

\section{TPM3}

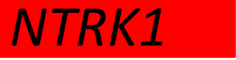

\section{Exon 7}

Exon 10

Figure 2: A. Fluorescence in situ hybridization (FISH) for break-apart of NTRK1 gene and B. TPM3-NTRK1 fusion with the 5'end of NTRK1, including the kinase domain, starting at exon 10 fused to exon 7 of TPM3 by NGS. 
Patient \#3. The third patient is a 68-year-old male who presented with metastatic gastric cancer with metastases to retroperitoneal lymph nodes and supraclavicular lymph nodes. The patient has HER 2 negative adenocarcinoma. The patient has received 12 cycles of FOLFOX and 8 cycles of irinotecan at the time of this writing. Although this patient had $\operatorname{Trk}(+)$ by IHC and FISH, NGS failed to find NTRK rearrangements because of poor quality of RNA.

\section{Confirmation of TPM3-NTRK1 fusion as an oncogenic driver in vitro}

TPM3-NTRK1 cDNA was cloned from KM12 cells by RT-PCR and TPM3-TrkA protein was expressed in Ba/F3 cells using lentiviral expression system. Two weeks after the $\mathrm{Ba} / \mathrm{F} 3$ cells were cultured in mIL3 and puromycin, the cells were further cultured in RPMI media without mIL3 and puromycin for additional 6 weeks. The cells showed robust growth without mIL3, confirming its oncogenic driving ability. Expression of TPM3-TrkA protein was confirmed by Flow-cytometry and qPCR. Subsequently, Ba/F3-TPM3TrkA cells were treated with entrectinib for 3 days and the cell viability was accessed using CellTiter-Glo ${ }^{\circledR}$ reagents. As expected, entrectinib inhibits the cell proliferation and the IC50 value is the same as what was obtained from PDCs (Figure $3 \mathrm{~A}$ and 3B). Similar western blot profiles were observed in these cells (data not shown)

\section{TPM3-NTRK1 rearrangement positive patient derived cells from metastatic lymph nodes of CRC patient \#1}

Patient-derived tumor cells (PDCs) were established from metastatic lymph nodes from patient \#1. After cytological confirmation, the PDCs were treated with entrectinib. Entrectinib is a potent, selective, orally available, ATP-competitive inhibitor of tyrosine kinases TrkA, TrkB, TrkC, ROS1 and ALK (encoded by NTRK1, NTRK2, NTRK3, ROS1 and ALK genes, respectively). The presence of NTRK1 rearrangement was confirmed in PDCs by genomic profiling (not shown). This tumor is negative for ROS1 and $A L K$ gene rearrangement or protein expression (data not shown). The IC50 from the conventional MTT assay demonstrated $0.0082 \mathrm{uM}$ entrectinib (Figure 3B). Using high-throughput 3-dimensional culture system, the IC50 was $0.089 \mathrm{uM}$ for entrectinib in NTRK1 rearranged colon cancer PDCs (Figure 3C). Western blot revealed that entrectinib potently inhibited TrkA phosphorylation and targeted downstream pathways (Figure 3D).

\section{DISCUSSION}

In this study, the incidence of TrkA (encoded by NTRK1) IHC positivity is $1.5 \%$ in gastric cancer and $2.7 \%$ in colorectal cancer patients by IHC. Both of the TrkA IHC positive CRC cases were confirmed to have TPM3-
NTRK1 rearrangements. However, the two TrkA IHC+ GC patients were not positive for NTRK1 FISH. From this data, we have demonstrated that IHC is a viable screening strategy for NTRK1 rearrangements in CRC. Tumor cells derived from one of the two TrkA IHC+ CRC patients were sensitive to a potent pan-TrkA inhibitor, entrectinib, with inhibition of downstream pathways, suggesting that NTRK1 rearrangements in non-lung or non-thyroid cancer can be a potent actionable genetic aberration as in NSCLC [18].

Since the first discovery of the TPM3-NTRK1 fusion in a colon cancer sample in 1982 [3], clinical development targeting this molecular subset has not been highlighted in metastatic colon cancer. Recently, Ardini et al used TrkA IHC to identify one TPM3-NTRK1 rearrangement out of 66 patients tested [18], demonstrating a prevalence of $1.5 \%$ that is comparable to what is observed in the cohort described here $(2.7 \%)$. Both of TrkA CRC cases reported here were $K R A S$ wild-type and $B R A F$ wild-type, whereas the case reported by Ardini et al was $K R A S$ wildtype. [18] However, in one GC, we failed to prove NTRK rearrangements by NGS due to poor quality of RNA and the existence of NTRK1 rearrangement in GC remained to be proven in the near future.

The clinical benefit from targeting NTRK1 fusions is being tested in ongoing phase I/II entrectinib clinical trials. Entrectinib is an orally available, potent and selective ATP-competitive pan-Trk, ROS1 and $A L K$ inhibitor with IC50 activities against TrkA. TrkB and TrkC of $<10 \mathrm{nM}$ [19]. In this report, we successfully established patient tumor cells from a TPM3-NTRK1 fusion $\mathrm{CRC}$ patient and demonstrated that these cells were potently inhibited by entrectinib at an IC50 of $8.2 \mathrm{nM}$ in the conventional MTT assay and $89 \mathrm{nM}$ in 3-dimentional high throughput drug screening system. Although more data needs to be accumulated to demonstrate the concordance between responses to therapy in patient derived tumor cells and the actual tumor response in the corresponding patient, it is very promising that the tumor cells from patients with TPM3-NTRK1 fusion gene dramatically responded to entrectinib. Of note, we also demonstrated that the four TrkA IHC+ patients were all negative for rearrangements in NTRK2, NTRK3, ROS1 and ALK, precluding alternative target effects besides TrkA (NTRK1 gene). Re-expression of TPM3-NTRK1 in $\mathrm{Ba} / \mathrm{F} 3$ further confirms that TPM3-TrkA fusion protein along is capable to be oncogenic driver. Therefore Inhibition of the TrkA kinase is a promising targeted therapy for cancer patients whose tumors harbor a NTRK1 rearrangement.

\section{MATERIALS AND METHODS}

\section{Patients}

This study included GC and CRC patients who were on palliative chemotherapy at Samsung Medical Center, 
A

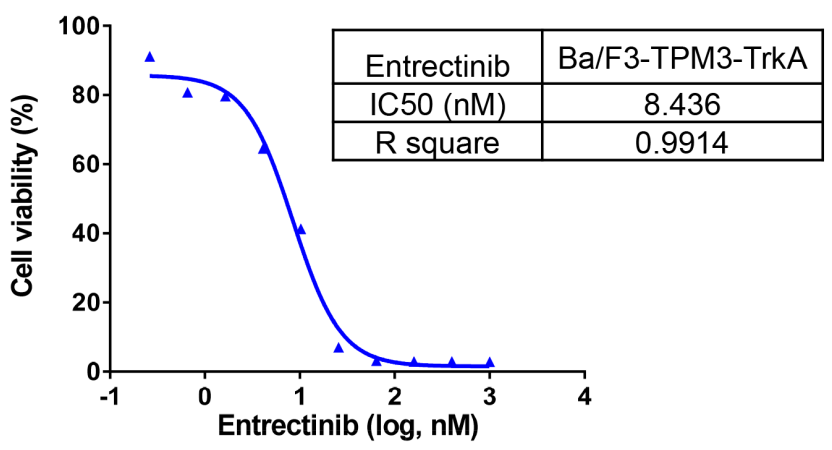

B

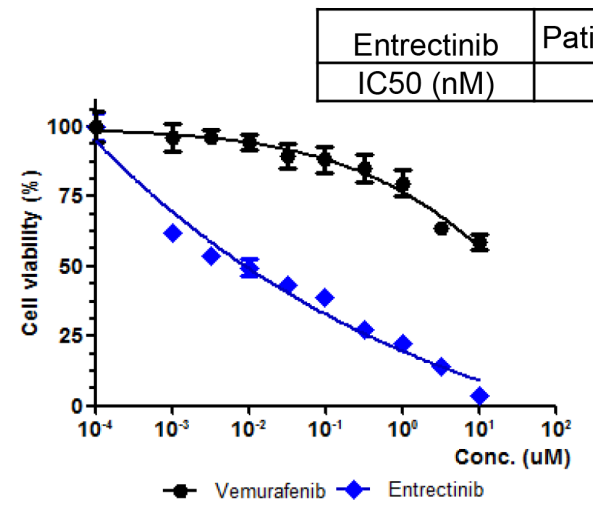

C

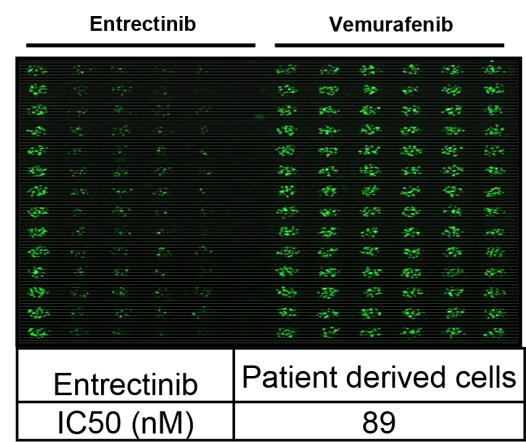

D

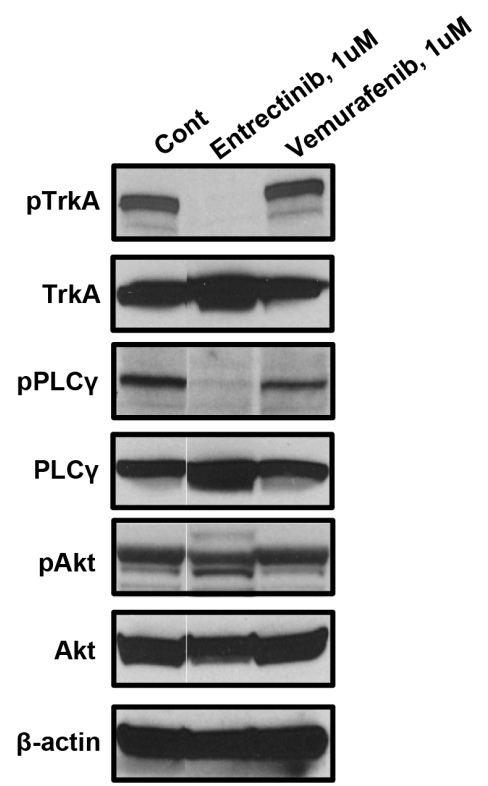

Figure 3: The conventional MTT assay for entrectinib using A. Ba/F3 cell and $\mathbf{B}$. patient derived cells, $\mathbf{C}$. The evaluation of IC50 for entrectinib using the high-throughput 3-dimensional culture system and D.The western blot for TrkA phosphorylation and targeted downstream pathways.

Seoul, Korea, between January 2014 and December 2014. All study participants provided written informed consent before study entry. Briefly, patients with metastatic solid tumors who may be eligible for clinical trial enrollment were eligible to enter the study. Patients also consented for in vitro establishment of patient-derived cells (PDCs) for research use if tissue was available.

\section{Immunohistochemistry for Trk}

Briefly, $4 \mu \mathrm{m}$ tissue sections were deparaffinized and rehydrated, and antigens were retrieved for $40 \mathrm{~min}$ in a citrate buffer $(\mathrm{pH} 6.1)$ at $95^{\circ} \mathrm{C}$. We used panTRK (C17F1 Rabbit mAb; 1: 100 dilution; Cell Signaling) as the primary antibody incubating 15 min with Bond-max autoimmunostainer (Leica Biosystem, Melbourne, Australia). DAB was used as the chromogen, and the sections were counterstained with hematoxylin. For positive control, we used KM12 cell line, which is known to have a TPM3-NTRK1 rearrangement.

\section{Fluorescence in situ hybridization (FISH)}

For analysis of NTRK1 gene rearrangements by fluorescence in situ hybridization (FISH), in cases of positive results of TrkA overexpression by IHC, we used ZytoLight SPEC NTRK1 Dual Color Break Apart Probe for the detection of translocations involving the NTRK1 gene at 1q23.1 (ZytoVision, Bremerhaven, Germany) according to the operating instructions. With the use of appropriate filter sets, the interphases of normal cells or cells without a translocation involving the 1q23.1 band, two green/orange fusion signals appear. A 1q23.1 locus affected by a translocation is indicated by one separate green signal and one separate orange signal. A threshold of $15 \%$ nuclei positive for break apart signals was used to establish the cut off for positive FISH.

\section{Next generation sequencing (NGS)}

FFPE tissue sections of $10 \mu \mathrm{M}$ thickness were microdissected to enrich tumor sample, as identified on 
a proximal H\&E slide, prior to nucleic acid extraction. Next generation sequencing (NGS) of extracted RNA was performed to identify gene rearrangements in NTRK1, NTRK2, NTRK3, ROS1 and ALK [15]. Briefly, the test consists of library preparation using anchored multiplex PCR coupled to sequencing on an Illumina MiSeqDx system.

\section{Ba/F3-TPM3-TrkA cell generation and proliferation assay}

To generate $\mathrm{Ba} / \mathrm{F} 3$ cells expressing TPM3-TrkA, TPM3-TrkA cDNA was cloned from KM12 cells by RT-PCR and inserted into a lentiviral vector pVL-EF1a-MCS-IRES-Puro (BioSettia, San Diego, CA). After confirmation by direct sequencing, VSVG-pseudo-typed lentivirus containing TPM3-TrkA cDNA was introduced into the murine IL-3 dependent pro-B cell $\mathrm{Ba} / \mathrm{F} 3$. The transduced $\mathrm{Ba} / \mathrm{F} 3$ cells were selected at 1 $\mathrm{ug} / \mathrm{mL}$ of puromycin in the murine IL-3 containing RPMI and $10 \%$ FBS media for two weeks. The stable cell pools were further selected in RPMI and 10\% FBS media without murine IL-3 for 4 weeks. To evaluate the anti-proliferative activity of entrectinib, Ba/F3-TPM3-TrkA cells were seeded at 5,000 cells per well in 96-well assay white plates (Costar \#3610) with different concentrations of Entrectinib ( 0 to $1 \mu \mathrm{M})$ at duplicates. Three days after incubation, cell viabilities were measured by luciferase-based ATP level detection using CellTiter-Glo ${ }^{\circledR}$ reagents (Promega, Madison, WI, USA) and IC50s were determined by 4-parameter curve fit with variable slope.

\section{Patient-derived cell culture and reagents}

Patient derived cell cultures were established as previously described [16]. Tumors were removed using core biopsy from a supraclavicular lymph node and then homogenized. Extracted cells were cultured in RPMI media supplemented with $10 \%$ fetal bovine serum, $0.5 \mathrm{~g} / \mathrm{ml}$ of hydrocortisone (Sigma Aldrich), $5 \mathrm{~g} / \mathrm{ml}$ of insulin (PeproTech, Rocky Hill, NJ, USA), 5 ng of EGF and FGF (PeproTech). Vemurafenib was purchased from Selleck Chemical (Houston, TX, USA). Entrectinib was provided by Ignyta, Inc. (San Diego, CA, USA). After pathologic confirmation, cells were seeded at $1 \times 10^{6}$ cells $/ 10 \mathrm{~mm}$ dishes or 5000 cells/well/96well plate and treated with $1 \mu \mathrm{M}$ of entrectinib. Treated cells were incubated for 72 hours at $37^{\circ} \mathrm{C}$ in a humidified atmosphere of 5\% carbon dioxide. These conditions were used for analysis of Immunoblotting and cell proliferation inhibition assays, which were run in triplicate. Entrectinib is a TrkA, TrkB, TrkC, ALK, ROS1 inhibitor that is currently undergoing a phase $1 / 2$ clinical trial in the US (http://www.clinicaltrials.gov; NCT02097810) and a first in human study in Italy [14]. Inhibition of tumor derived cell line proliferation was determined using CellTiter-Glo ${ }^{\circledR}$ reagents (Promega, Madison, WI, USA) according to the manufacturer's protocol. For 3-dimensional drug screening system, we utilized the S+ Chip Analyzer (Samsung Electro-Mechanics Co., Ltd, South Korea) to analyze the image of the cells grown in $3 \mathrm{D}$ droplets on micropillars as previously described [17]. Briefly, for intensity measurement, the software defines the boundary of analysis as each micropillar edge and calculates mean intensity by dividing total green fluorescence intensities (represented by 8 bit values) in the micropillar with the total pixels of the micropillar (boundary of analysis). In case of the area, the software counts the number of pixel whose intensity is more than background (established as 30, in the 8 bit green range) and calculates area of the colonies [17].

\section{Immunoblot analysis}

Total proteins from patient tumor derived cell lines were isolated using RIPA buffer (Sigma-Aldrich, St. Louis, MO, USA) containing a protease inhibitor cocktail (Roche, Mannheim, Germany) and phosphatase inhibitor cocktail (Roche).Protein concentrations were determined according to Bradford procedure using a Quick Start Bradford Protein Assay (Bio-Rad, Hercules, CA, USA). Thirty $\mu \mathrm{g}$ of proteins were subjected to $10 \%$ SDS-polyacrylamide gel electrophoresis, and electro-transferred onto nitrocellulose membranes. The membranes were blocked with 5\% nonfat dry milk in Tris-buffered saline containing $0.1 \% \mathrm{v} / \mathrm{v}$ Tween 20, and probed overnight at $4{ }^{\circ} \mathrm{C}$ with specific antibodies: pTrakA(Tyr490), TrkA, pPLC $\gamma 1($ Tyr783), PLC $\gamma 1$, pAkt(Ser473) and Akt from Cell Signaling Technology (Beverly, MA, USA) and beta actin from Sigma Aldrich. Horseradish peroxidase-conjugated anti-rabbit or mouse IgG (Vector, Burlingame, CA, USA) were used as secondary antibodies. Immune complexes were visualized by enhanced chemiluminescence using ECL Western Blotting Substrate (Thermo Scientific, Rockford, IL, USA).

\section{ACKNOWLEDGMENTS AND GRANT SUPPORT}

This research was supported by a grant of the Korea Health Industry Development Institute (KHIDI), funded by the Ministry of Health \& Welfare, Republic of Korea (grant number: HI13C2096, HI13C1951, HI14C3418).

\section{CONFLICTS OF INTEREST}

No conflicts of interest.

\section{REFERENCES}

1. Chao MV. Neurotrophins and their receptors: a convergence point for many signalling pathways. Nat Rev Neurosci. 2003; 4:299-309. 
2. Kaplan DR, Miller FD. Neurotrophin signal transduction in the nervous system. Curr Opin Neurobiol. 2000; 10:381-391.

3. Pulciani S, Santos E, Lauver AV, Long LK, Aaronson SA, Barbacid M. Oncogenes in solid human tumours. Nature. 1982; 300:539-542.

4. Martin-Zanca D, Hughes SH, Barbacid M. A human oncogene formed by the fusion of truncated tropomyosin and protein tyrosine kinase sequences. Nature. 1986; 319:743-748.

5. Greco A, Miranda C, Pagliardini S, Fusetti L, Bongarzone I, Pierotti MA. Chromosome 1 rearrangements involving the genes TPR and NTRK1 produce structurally different thyroid-specific TRK oncogenes. Genes Chromosomes Cancer. 1997; 19:112-123.

6. Greco A, Miranda C, Pierotti MA. Rearrangements of NTRK1 gene in papillary thyroid carcinoma. Mol Cell Endocrinol. 2010; 321:44-49.

7. Alberti L, Carniti C, Miranda C, Roccato E, Pierotti MA. RET and NTRK1 proto-oncogenes in human diseases. J Cell Physiol. 2003; 195:168-186.

8. Wiesner T, He J, Yelensky R, Esteve-Puig R, Botton T, Yeh I, Lipson D, Otto G, Brennan K, Murali R, Garrido M, Miller VA, Ross JS, et al. Kinase fusions are frequent in Spitz tumours and spitzoid melanomas. Nat Commun. 2014; 5:3116.

9. Ross JS, Wang K, Gay L, Al-Rohil R, Rand JV, Jones DM, Lee HJ, Sheehan CE, Otto GA, Palmer G, Yelensky R, Lipson D, Morosini D, et al. New routes to targeted therapy of intrahepatic cholangiocarcinomas revealed by nextgeneration sequencing. Oncologist. 2014; 19:235-242.

10. Stransky N, Cerami E, Schalm S, Kim JL, Lengauer C. The landscape of kinase fusions in cancer. Nat Commun. 2014; 5:4846.

11. Wu G, Diaz AK, Paugh BS, Rankin SL, Ju B, Li Y, Zhu X, Qu C, Chen X, Zhang J, Easton J, Edmonson M, Ma X, et al. The genomic landscape of diffuse intrinsic pontine glioma and pediatric non-brainstem high-grade glioma. Nat Genet. 2014; 46:444-450.

12. Ricarte-Filho JC, Li S, Garcia-Rendueles ME, Montero-Conde C, Voza F, Knauf JA, Heguy A, Viale A,
Bogdanova T, Thomas GA, Mason CE, Fagin JA. Identification of kinase fusion oncogenes in post-Chernobyl radiation-induced thyroid cancers. J Clin Invest. 2013; 123:4935-4944.

13. Vaishnavi A, Le AT, Doebele RC. TRKing down an old oncogene in a new era of targeted therapy. Cancer Discov. $2015 ; 5: 25-34$.

14. Lee J, Lee SE, Kang SY, Do IG, Lee S, Ha SY, Cho J, Kang WK, Jang J, Ou SH, Kim KM. Identification of ROS1 rearrangement in gastric adenocarcinoma. Cancer. 2013; 119:1627-1635.

15. Zheng Z, Liebers M, Zhelyazkova B, Cao Y, Panditi D, Lynch KD, Chen J, Robinson HE, Shim HS, Chmielecki J, Pao W, Engelman JA, Iafrate AJ, et al. Anchored multiplex PCR for targeted next-generation sequencing. Nat Med. 2014; 20:1479-1484.

16. Lee JY, Kim SY, Park C, Kim NK, Jang J, Park K, Yi JH, Hong M, Ahn T, Rath O, Schueler J, Kim ST, Do IG, et al. Patient-derived cell models as preclinical tools for genomedirected targeted therapy. Oncotarget. 2015; 6:25619-25630.

17. Lee DW, Choi YS, Seo YJ, Lee MY, Jeon SY, Ku B, Kim S, Yi SH, Nam DH. High-throughput screening (HTS) of anticancer drug efficacy on a micropillar/microwell chip platform. Anal Chem. 2014; 86:535-542.

18. Ardini E, Bosotti R, Borgia AL, De Ponti C, Somaschini A, Cammarota R, Amboldi N, Raddrizzani L, Milani A, Magnaghi P, Ballinari D, Casero D, Gasparri F, et al. The TPM3-NTRK1 rearrangement is a recurring event in colorectal carcinoma and is associated with tumor sensitivity to TRKA kinase inhibition. Mol Oncol. 2014; 8:1495-1507.

19. Filippo G, De Braud LP, Monica Niger, Silvia Damian, Benedetta Bardazza, Antonia Martinetti, Giuseppe Pelosi, Giovanna Marrapese, Laura Palmeri, Giulio Cerea, Emanuele Valtorta, Silvio Veronese, Andrea SartoreBianchi, Elena Ardini, Marcella Martignoni, Arturo Galvani, Paul Pearson, David Luo, James L. Freddo, Salvatore Siena. Phase 1 open label, dose escalation study of RXDX101, an oral pan-trk, ROS1, and ALK inhibitor, in patients with advanced solid tumors with relevant molecular alterations. J Clin Oncol. 2014; 32. 